\title{
A acção sindical na UE e MERCOSUL: Limites e desafios
}

Trade Union Action in the EU and MERCOSUR: Limits and Challenges

L'action syndical à l'U.E. et au MERCOSUR : Limites et défis

Hermes Augusto Costa

\section{CpenEdition}

\section{Journals}

Edição electrónica

URL: http://journals.openedition.org/rccs/1301

DOI: $10.4000 /$ rccs. 1301

ISSN: $2182-7435$

\section{Editora}

Centro de Estudos Sociais da Universidade de Coimbra

\section{Edição impressa}

Data de publição: 1 Junho 2002

Paginação: 69-96

ISSN: 0254-1106

\section{Refêrencia eletrónica}

Hermes Augusto Costa, " A acção sindical na UE e MERCOSUL: Limites e desafios », Revista Crítica de Ciências Sociais [Online], 62 | 2002, colocado online no dia 01 outubro 2012, criado a 21 abril 2019. URL : http://journals.openedition.org/rccs/1301; DOI : 10.4000/rccs.1301 


\section{HERMES AUGUSTO COSTA}

Faculdade de Economia da Universidade de Coimbra e Centro de Estudos Sociais

\section{A acção sindical na UE e MERCOSUL: Limites e desafios*}

Este artigo centra-se na discussão dos limites e desafios colocados à acção sindical na União Europeia (UE) e no Mercado Comum do Sul (MERCOSUL). Sugere-se que, não obstante os diferentes graus de consolidação daqueles blocos regionais se poderem traduzir igualmente em práticas sindicais de distintos andamentos, é possível encontrar algumas simetrias quanto às dificuldades enfrentadas pelo sindicalismo de ambos os espaços. São ainda passadas em revista as principais etapas sociais de ambos os blocos e, na sequência da exposição dos principais desafios enfrentados pelo sindicalismo europeu e do MERCOSUL, são avançadas algumas propostas para uma cooperação sindical envolvendo o sindicalismo português e o brasileiro.

\section{Introdução}

Portugal e o Brasil são dois países com pesos económicos distintos nos blocos regionais em que estão inseridos. Portugal ocupa uma posição periférica num bloco regional consolidado - a União Europeia (UE) -, ao passo que o Brasil ocupa uma posição central num bloco regional que busca consolidar-se - o Mercado Comum do Sul (MERCOSUL). ${ }^{1}$ Como sustenta

\footnotetext{
* Versões prévias deste texto foram apresentadas no seminário "CUT: Discutindo Novos Caminhos", organizado pela Escola Sindical de São Paulo e realizado no Sindicato dos Químicos e Plásticos de São Paulo, 13-15 de Junho de 2000, e num seminário sobre "sindicalismo regional" que apresentei para investigadores do Centro de Estudos dos Direitos da Cidadania (CENEDIC) da Universidade de São Paulo, realizado a 8 de Junho 2001. A investigação empírica que realizei em São Paulo (Maio/Junho de 2000 e Junho de 2001) foi apoiada pelo Convénio entre o Instituto de Cooperação Científica e Tecnológica Internacional (ICCTI) e a Coordenação de Aperfeiçoamento do Pessoal de Nível Superior (CAPES). Agradeço aos investigadores do Centro de Estudos Sociais e do CENEDIC os comentários e sugestões que fizeram a essas versões.

${ }^{1}$ Enquanto no MERCOSUL (Brasil, Argentina, Uruguai e Paraguai), a economia brasileira é responsável por cerca de 70\% do Produto Interno Bruto (PIB) (Pereira, 1999: 7; Veiga, 1999: 25), na UE a economia portuguesa encontra-se muito aquém da média europeia. De acordo com uma estimativa do Banco Espírito Santo, apenas no ano de 2051 é que o PIB per capita português, medido em paridades do poder de compra, atingirá a média da UE (Expresso, 10.06.2000). Segundo alguns (Sá et al., 2001), em 2008 o nível de vida português poderá mesmo ser ultrapassado pelo grego, agravando os cenários de divergência relativamente à UE.
} 
Boaventura de Sousa Santos, ainda que ambos os países estejam sob pressão dos imperativos do capitalismo global, "o Brasil está na zona de influência do capitalismo liberal dos Estados Unidos e Portugal está na zona de influência do capitalismo social-democrático europeu" (Santos, 2000: 54). Mas será o peso económico diferenciado destes e de outros países de ambos os blocos regionais igualmente traduzível em desequilíbrios quanto ao modo de analisar a acção sindical? Que papel ficou, afinal, reservado aos sindicatos na edificação de uma "dimensão social" nos dois blocos? Quais as principais etapas dessa dimensão? Que limitações e desafios se colocam hoje aos sindicatos na UE e no MERCOSUL? Serão tais limitações e desafios desajustáveis entre ambos os blocos ou é admissível a sua partilha? O que pode aproximar o sindicalismo de países como Portugal e o Brasil?

É em torno destas e de outras interrogações que pretendo orientar a minha reflexão. Em primeiro lugar, proponho algumas ideias gerais sobre o modo como pensar a relação entre o sindicalismo nacional e transnacional. Em segundo lugar, abro um espaço (que prolongo na terceira e quarta partes) de análise relacional entre o MERCOSUL e a UE. Não obstante as diferenças verificadas entre ambos no que diz respeito aos ritmos de integração regional, procuro identificar uma "agenda comum" das dificuldades sindicais nos dois blocos regionais. Em terceiro lugar, são enunciadas as principais etapas da participação social e sindical na UE e MERCOSUL, a partir das quais se vislumbram, em quarto lugar, alguns desafios ou possibilidades de acção sindical em ambos os espaços regionais. Como prolongamento dessas possibilidades tratarei, por fim, de avançar algumas sugestões para o reforço da cooperação sindical em língua portuguesa.

\section{Ideias gerais sobre a relação entre o sindicalismo nacional e transnacional}

A percepção das realidades que transcendem os espaços nacionais - como a UE e o MERCOSUL aqui em discussão na óptica da acção sindical - põe em confronto as escalas de análise nacional e transnacional. Na verdade, quando pensamos nas realidades sindicais transnacionais, somos confrontados, por um lado, com a existência de estruturas sindicais que, para além de poderem acolher no seu seio organizações sindicais nacionais, pautam a sua actuação por lógicas de harmonização e articulação que superam o mero espaço de referência nacional. Por outro lado, porém, a presença das organizações sindicais nacionais permanece forte, dela dependendo também em grande medida o sucesso das possíveis coligações e alianças transnacionais do sindicalismo. Daí que, quer as escalas sejam locais, nacionais, 
regionais ou globais, a atitude mais recomendável deverá passar, como aponta Manuel Carvalho de Silva (2000a), não só pela sua apropriação enquanto objecto de análise, como pela promoção da articulação entre os diferentes níveis que lhes subjazem.

Atentemos então na sugestão de algumas formas possíveis de pensar a relação entre o sindicalismo nacional e transnacional.

1. Falar em transnacionalização do sindicalismo significa constatar a existência de algo que potencialmente se constitui como uma reacção a outra(s) forma(s) de transnacionalização gerada(s) no campo da economia, vulgarmente designada(s) por globalização económica. Grosso modo, perante o protagonismo das empresas multinacionais, a atitude do sindicalismo apresenta-se como reactiva.

2. Esta atitude sindical reactiva não deve dissociar-se do facto de a organização sindical transnacional, por não ser prioritária, ter estado quase sempre arredada das preocupações centrais dos responsáveis sindicais. Porém, a construção de blocos comerciais e os processos de internacionalização da economia aumentaram o estímulo para a cooperação transnacional entre organizações sindicais, desencadeando respostas e/ou estimulando iniciativas.

3. Por sua vez, a organização de respostas e/ou iniciativas sindicais, se bem que tendencialmente menos enquadrada pela acção dos Estados nacionais, continua a conceder prioridade às políticas nacionais. Isto significa que os processos de harmonização transnacional das práticas sindicais não anulam o peso dos factores nacionais. Com efeito, um olhar para o interior dos espaços sindicais nacionais revela-nos sinais de diversidade que condicionam quer a acção nacional do sindicalismo, quer as práticas sindicais transnacionais.

4. No entanto, apesar de a diversidade sindical nacional condicionar a acção do sindicalismo, ela também não é incompatível com ambições mais vastas de acção supranacional. Assim sendo, quando o discurso sindical não é estritamente nacional, ele tende a ser substituído preferencialmente por uma vinculação ao patamar transnacional que geograficamente lhe está mais próximo, seja ele a UE, o MERCOSUL, ou o Acordo de Livre Comércio da América do Norte (NAFTA), por exemplo. É, aliás, neste sentido que os blocos económicos regionais podem cumprir uma importante função de intermediação entre raízes sindicais nacionais e opções laborais globais.

5. Os blocos económicos regionais que buscam consolidar-se (como o MERCOSUL) podem ser objecto de "disputa" por parte de outros blocos. Isto significa que a construção de estratégias sindicais de âmbito regional 
está sujeita quer ao confronto com, quer à atractividade de "modelos sociais" de outros blocos. Esta hipótese torna mais ténues as possíveis formas de solidariedade sindical transnacional em construção.

Este conjunto de ideias gerais acabadas de enunciar deixa antever um misto de oportunidades e de limitações para o sindicalismo. Identifico, de seguida, algumas dessas limitações.

\section{Uma "agenda comum" de dificuldades entre UE e MERCOSUL?}

Como tive já oportunidade de mencionar, o grau de maturidade do MERCOSUL está ainda distante daquele em que se encontra a UE, embora esse facto não impeça que se possa sugerir uma resposta afirmativa à interrogação levantada quanto a uma "agenda comum" de dificuldades. E mesmo tendo em conta que o nascimento do sindicalismo europeu foi bem mais precoce do que o surgimento do sindicalismo da América do Sul, são detectáveis sinais de convergência no que diz respeito à identificação e vivência de alguns problemas.

No caso europeu, e em particular nos anos 90, vários autores têm vindo a defender que a crescente europeização das relações laborais não é sinónimo de desnacionalização (Traxler e Schmitter, 1995; Streeck e Schmitter, 1998; Streeck, 1998). Isto reflecte-se, consequentemente, na acção sindical e permite a identificação de um conjunto de dificuldades à transnacionalização do sindicalismo: raízes sindicais predominantemente nacionais; fraca teorização sobre o tema; diferenças de país para país em matéria legislativa; interferência (quer por oposição, quer por conivência) de actores patronais e estatais; competitividade intra-sindical; atitudes sindicais de resistência/ proteccionismo; insuficiente apoio de instituições regionais de regulação laboral; débil apetência para abrir mão de um "exclusivo" assente em interesses sindicais (Costa, 2001: 121-122). Inclusive no âmbito da maior organização sindical europeia - a Confederação Europeia de Sindicatos (CES) podem identificar-se também algumas limitações: muitos sindicatos filiados na CES permanecem vinculados a perspectivas e objectivos nacionais; a ausência de um suporte financeiro adequado proveniente das organizações filiadas fez com que esta organização ficasse muito dependente dos apoios provenientes da Comissão Europeia, tornando-se vulnerável às mutações políticas ocorridas dentro desta e, consequentemente, suscitando dúvidas sobre a "independência" da política seguida pela CES; incapacidade de promover uma identidade transnacional entre trabalhadores (Waddington et al., 1997: 485; Waddington, 1999: 14). Assim sendo, num contexto generalizado de mutação das identidades sindicais (Hyman, 1996, 1999), onde porventura será ajustado falar de uma identidade sindical europeia difusa 
(Costa, 2000: 174), pensar em alternativas identitárias ${ }^{2}$ é um caminho desejável pois nem sempre as iniciativas sindicais são convergentes com a ideia de integração regional.

Por outro lado, no contexto do MERCOSUL, os obstáculos à trasnacionalização do sindicalismo não são menores $^{3}$ nem muito distintos dos identificados no espaço europeu. Como sugere Vigevani (1998: 291), de entre os obstáculos que se colocam a uma acção sindical no MERCOSUL, destacam-se: os de ordem histórica, dada a preponderância do espaço de actuação sindical nacional; os de ordem material, pois são necessários grandes recursos financeiros para suportar uma acção transnacional; os de ordem política, que pressupõem que é necessário lidar com distintos interesses sindicais consolidados nacionalmente; os de ordem cultural, pois a actuação sindical está muitas vezes orientada para uma lógica imediatista, assente em reivindicações salariais, o que, no fundo, significa a necessidade de substituir uma visão de curto prazo por orientações de teor estratégico; e, por fim, obstáculos que se prendem com os ritmos de integração regional, pois a criação de direitos iguais entre os quatro países do MERCOSUL está dependente da progressão deste a caminho de um verdadeiro "mercado comum". Mas a este conjunto de obstáculos poderíamos ainda acrescentar outros, como salienta, no Brasil, a Central Única dos Trabalhadores (CUT): obstáculos de ordem legal, resultantes da inexistência de sistemas legais uniformes; obstáculos relacionados com a vinculação às normas internacionais de trabalho, pois não existe uniformidade na adesão às convenções da Organização Internacional do Trabalho (OIT); ou ainda, obstáculos associados à aplicação de tais normas, pois a ratificação de convenções nem sempre se traduz no seu cumprimento (CUT, 2000: 1).

\section{Calendarizando a transnacionalização do social}

O levantamento de algumas dificuldades de actuação sindical à escala europeia e à escala do MERCOSUL ajuda, pois, a delimitar uma "agenda comum" de problemas em ambos os espaços, sem que isso possa ou deva

\footnotetext{
2 Para uma sugestiva análise de algumas identidades sindicais alternativas, cf. Hyman, 1996: 70-73, 1999: 128-130; cf. também, em Dølvik, 2000: 62, a selecção de algumas características paradoxais associadas ao padrão de sindicalismo europeu.

3 Segundo Boaventura de Sousa Santos, os países periféricos e semiperiféricos no contexto mundial são os que se encontram mais sujeitos às imposições neoliberais, uma vez que estas são transformadas pelas agências financeiras multilaterais (Fundo Monetário Internacional e Banco Mundial) em condições para a renegociação da dívida externa, através de programas de ajustamento estrutural (Santos, 2001:37, 42, 44-45). Além disso, "os países do MERCOSUL sofrem as consequências de um maior grau de exposição comercial externa (intra- e extra-região) sem o devido aprofundamento dos níveis de integração económica e política que seria esperado" (Castro, 1999a: 68).
} 
ser visto como um elemento obscurecedor das diferenças entre eles. $\mathrm{Na}$ verdade, ao procurar assinalar, nesta terceira parte, as principais etapas da participação social e sindical na UE e no MERCOSUL, saltam de novo à vista timings diferenciados, que são o reflexo directo dos ritmos imprimidos à "dimensão social".

No contexto da UE, alguns avanços importantes deram forma à ideia de Europa Social: ${ }^{4}$ i) o Tratado de Roma (1957), que, apesar de conter poucas disposições no domínio social e de perspectivar o "social" como projecto nacional, lançou as bases para uma política social europeia; ii) o Comité Económico e Social, instituído pelo Tratado e representando os parceiros sociais tradicionais (patrões e sindicatos), bem como diversos grupos de interesses da comunidade, discutindo uma pluralidade de políticas; iii) o Acto Único Europeu (1987), que consagrou o conceito de "mercado interno", acrescentando ao Tratado de Roma disposições relativas à melhoria do ambiente no meio de trabalho, ao diálogo social e à coesão económica e social; iv) a Carta Comunitária dos Direitos Sociais Fundamentais dos Trabalhadores (1989), que consagra, no plano comunitário, um conjunto de princípios aplicáveis à protecção dos trabalhadores e estabelece os grandes princípios em que se baseia o modelo europeu de direito do trabalho; v) o Tratado de Maastricht (1992), que abriu caminho a maior aprofundamento e integração da então Comunidade Europeia e que incidiu tanto na consolidação dos direitos sociais fundamentais dos trabalhadores (na forma como eles estavam expressos na Carta Comunitária), como no desenvolvimento de acções em domínios como a exclusão social, os deficientes, a pobreza ou a integração dos migrantes de "países terceiros"; vi) nesta sequência, seria aprovado um Protocolo a Doze autorizando um Acordo a Onze sobre a Política Social devido à intenção de exclusão manifestada pelo Reino Unido, que não se associou à Carta por pretender que todas as disposições fossem aprovadas por unanimidade. O Protocolo trouxe consigo algumas alterações importantes tais como: uma competência legal mais alargada de intervenção no domínio da política social da UE; um maior espaço para a votação por maioria qualificada; um reforço do papel dos "parceiros sociais" europeus, reconhecendo-lhes a possibilidade de negociarem acordos colectivos europeus; vii) a Directiva 94/45/CE que, em 1994, implementou os Conselhos de Empresa Europeus (CEEs), destinados a instituir mecanismos de informação e consulta dos trabalhadores nas em-

\footnotetext{
${ }^{4}$ Identifico apenas aquelas que considero serem as etapas mais importantes neste domínio. Para uma exposição cronológica recente e exaustiva dos actos comunitários em matéria social, cf. Silva, 2000b: 76-92.
} 
presas ou grupos de empresa de dimensão comunitária; viii) o Tratado de Amsterdão (1997), que, entre outros pontos: recupera o texto do Acordo sobre a política social do Tratado de Maastricht, integrando-o no articulado do novo tratado; define os objectivos da UE no domínio da política social, fazendo explicitamente referência à Carta Comunitária dos Direitos Sociais Fundamentais dos Trabalhadores, de 1989; fixa as matérias sociais que carecem de aprovação por maioria qualificada; define as condições de intervenção dos parceiros sociais nos processos de decisão da Comunidade no domínio social; inclui um "capítulo sobre o emprego" onde se reafirma que a responsabilidade primeira no domínio do emprego cabe aos Estados-membros, embora estes passem a inscrevê-la doravante no quadro de uma estratégia coordenada a nível da Comunidade. Consequentemente, o domínio social fica associado ao económico, a promoção de um "nível elevado de emprego" consagra-se como um dos grandes objectivos de todas as políticas e actividades da UE, e prevê-se a criação de um Comité de Emprego encarregado de observar a evolução da política de emprego ao nível da UE.

Esta breve síntese das etapas-chave da Europa Social mostra quão longo foi o caminho percorrido. Na final do ano 2000, a aprovação de uma Carta dos Direitos Fundamentais da UE (no quadro da Cimeira Europeia de Nice) era vista como mais uma oportunidade de melhorar os conteúdos quer do Tratado de Amsterdão, quer da Carta dos Direitos Sociais Fundamentais dos Trabalhadores. Todavia, o facto de apenas ter recebido aprovação enquanto declaração política e não ser juridicamente vinculante deixou antever, desde logo, mais motivos de reivindicação para os sindicatos e, como tal, mais distâncias sociais a percorrer, tanto mais que as suas implicações se estenderão aos próximos Estados-membros que vierem futuramente a aderir à UE. Há, por isso, muito terreno a desbravar pelos sindicatos europeus, pelo que os sinais de progresso que possam depreender-se daquelas etapas da Europa Social apenas representam um motivo de satisfação parcial.

Ora, a história dos últimos 30 anos de acção sindical europeia foi, também ela, marcada por processos de afirmação progressiva que estiveram longe de ser o garante de uma identidade sindical europeia coesa. Sem dúvida que quando a CES se constituiu, em 1973, representou uma importante conquista para o sindicalismo europeu, mesmo que, de entre as organizações que a fundaram, não constassem apenas centrais sindicais do espaço que hoje coincide com a UE. A CES assumia-se, para além de mais forte representante dos trabalhadores europeus, como grupo de pressão e actor político (Goetschy, 1996: 258, 264). Mas enquanto herança directa da Con- 
federação Internacional dos Sindicatos Livres (CISL), a CES constituiu-se inicialmente num espaço de reunião das principais centrais sindicais europeias que se opunham ao sindicalismo comunista dos países de Leste. Ou seja, foram sobretudo diferenças ideológicas que dificultaram a criação de uma família sindical europeia comum e que permitiram que o protagonismo sindical em redor da CES fosse conduzido por organizações como os Trade Unions Congress (TUC) britânicos ou a Deutscher Gewerkschaftsbund (DGB) alemã, que combateram activamente o modelo de sindicalismo comunista reunido na Federação Sindical Mundial (FSM). Só no final dos anos 80 esta construção selectiva da europeização do sindicalismo conheceria transformações significativas, com a queda do Bloco de Leste. Este marcante acontecimento mundial abriria caminho a uma nova fase da participação do sindicalismo europeu no âmbito da UE. Expressão maior da representatividade sindical, a CES passou a assumir, por via do esvaziamento progressivo da FSM, um discurso e uma atitude cada vez mais plurais. ${ }^{5} \mathrm{Na}$ opinião de Jon Erik Dølvik (2000: 63) o 7. ${ }^{\circ}$ Congresso da CES, em 1991, constitui mesmo uma "Perestroika' a partir de cima", traduzida em profundas mudanças organizacionais ${ }^{6} \mathrm{com}$ o objectivo de "transformar a CES numa confederação sindical genuína capaz de conduzir a negociação colectiva europeia”. Por seu lado, os contextos envolventes dos $8 .^{\circ}$ e $9 .^{\circ}$ congressos da CES (realizados respectivamente em 1995 e 1999) confirmariam a abertura a novas organizações com fortes tradições de ligação a partidos comunistas. Refiro-me à filiação na CES de duas organizações de inegável representatividade à escala europeia: a Confederação Geral dos Trabalhadores Portugueses (CGTP), em Dezembro de 1994, e a Confédération Générale du Travail (CGT) francesa, em Março de 1999.

Por sua vez, alguns passos importantes no domínio social ajudam-nos a definir o elenco das práticas sindicais estabelecidas no âmbito do MERCOSUL. É que, apesar dos ritmos distintos de integração regional entre UE e MERCOSUL atrás referidos, este "pretende avançar na direcção de um mercado comum pleno e seguir o caminho, ainda que de forma sui generis, da UE”, distinguindo-se quer da integração norte-americana, via NAFTA, quer da integração continental, via Área de Livre Comércio das

\footnotetext{
${ }_{5}$ Composta por 74 Confederações Sindicais Nacionais provenientes de 34 países europeus, assim como por 11 Federações Sindicais Europeias, a CES possui um total de 60 milhões de membros filiados (ETUC, 2002: 1).

${ }^{6}$ A inclusão dos Comités Sindicais Europeus (hoje conhecidos por Federações Sindicais Europeias, FSEs) - estruturas sectoriais de representação sindical - enquanto membros da CES foi, entre outras, uma das mudanças decisivas desse Congresso; veja-se também a análise que Janine Goetschy (1996) faz dos principais momentos da história da CES.
} 
Américas $\left(\mathrm{ALCA}^{7}\right)$, pois estas formas de integração visam essencialmente a constituição de zonas de livre comércio (Chaloult e Almeida, 1999: 9). Tendo presente que o Protocolo de Ouro Preto (1994) veio conferir personalidade jurídica internacional ao MERCOSUL e definir uma nova estrutura institucional, podem indicar-se, também de modo sintético, os seguintes "passos sociais" principais do MERCOSUL: desde 1995, o Subgrupo 10 (Assuntos trabalhistas, emprego e segurança social, anteriormente designado de Subgrupo 11, de Assuntos Trabalhistas); a sua Comissão Ad Hoc sobre a "dimensão social do MERCOSUL"; o Fórum Consultivo Económico-Social (FCES), orgão de carácter consultivo composto, a partir de 1996, por empresários, centrais sindicais (estes dois em maior número) e outras entidades da sociedade civil e destinado a atender às consultas feitas por organismos inter-gorvernamentais; a Declaração Sóciolaboral do MERCOSUL (1998), que estabelece a criação de um orgão tripartido, a Comissão Sóciolaboral, e se torna num instrumento de protecção dos direitos laborais básicos. ${ }^{8}$

Se estas instâncias sociais se constituíram e foram progressivamente consolidando nos anos 90, não deve esquecer-se, porém, a existência da Coordenadora das Centrais Sindicais do Cone Sul (CCSCS $)^{9}$ que, desde

\footnotetext{
7 A ALCA é a designação do processo iniciado na Cimeira de Miami (proposta pela Administração Clinton), em Dezembro de 1994, destinado a negociar, até 2005, uma ampla zona de livre comércio no hemisfério americano, desde o Alasca até à Terra do Fogo (Roett, 1999: 2-3). Mas, na prática, trata-se, segundo o Secretário de Relações Internacionais da CUT, de uma extensão do NAFTA ao resto do Continente, pois nem sequer se salvaguardam as desigualdades económicas dos 34 países que participam nas negociações da ALCA, uma vez que só os três países que constituem o NAFTA (EUA, Canadá e México) representam 80\% do PIB do Continente, ao passo que o MERCOSUL é responsável por $8 \%$ do PIB e os outros 29 países por 12\% (Jakobsen, 1999: 241). Por seu lado, Dupas (1999: 133) acentua ainda mais essa décalage, atribuindo ao NAFTA 88\% do PIB do Continente. Cf. também Silva (1997: 1).

${ }^{8}$ Para uma análise mais atenta e contextualizada das instâncias sociais do MERCOSUL, consultem-se vários dos artigos publicados em Chaloult e Almeida (orgs.), 1999, bem como as análises aprofundadas de Castro (1999a: 46-67) ou da CUT/CSN (2000: 46-73). A título de complemento e de actualização, Castro (2000: 114-125) refere que, para além da importância atribuída à "Declaração Sóciolaboral", dois outros importantes avanços dos temas laborais merecem destaque: o Observatório Sobre o Mercado de Trabalho do MERCOSUL - disponível em www.observatorio.net -, que, de forma articulada com o SGT 10 (Subgrupo 10), busca "um acompanhamento dos mercados de trabalho nacionais e de cerca de dez sectores seleccionados, para conhecimento e difusão de informações sobre emprego, migrações trabalhistas, formação profissional, seguridade social, normas regulatórias do mercado de trabalho e as políticas e programas públicos sobre essas temáticas" (Castro, 2000: 117); e as negociações colectivas do MERCOSUL, exemplificadas pelo contrato colectivo da Volkswagen (Abril de 1999), que envolveu a participação de sindicatos metalúrgicos do Brasil e Argentina.

9 A CCSCS é um organismo de coordenação e actuação das organizações sindicais dos países do Cone Sul. Foi constituída em 1986, com o apoio da Organização Regional Interamericana dos Trabalhadores (ORIT), sendo composta por centrais sindicais dos quatro países do MERCOSUL, mas igualmente do Chile e da Bolívia (membros associados do MERCOSUL). Apesar de tanto na
} 
1986, foi criando condições para que tais instâncias pudessem ver a luz do dia. Na verdade, a "constituição de um fórum unitário e pluralista nos moldes da Coordenadora representa uma iniciativa inédita do movimento sindical latino-americano, historicamente caracterizado pela debilidade estrutural e por uma profunda divisão, originada na diversidade de concepções e culturas sindicais predominante nos países da região" (Veiga, 1993: 200). É precisamente esse contexto de meados dos anos 80 que nos reconduz, em concreto, às principais etapas da participação sindical do MERCOSUL. Segundo alguns autores (Vigevani, 1998: 78-82; Vigevani e Mariano, 1998: 86), a participação sindical no MERCOSUL passou por três fases:

A primeira fase, entre 1986 e 1991, vai desde os acordos entre Alfonsin e Sarney - destinados a estreitar relações bilaterais entre a Argentina e o Brasil em matéria de integração, cooperação e desenvolvimento - até à assinatura do Tratado de Assunção (26.03.1991). Nesta fase, o sindicalismo atribuiu pouca importância ao processo de integração por entender que ele não iria ter sequência futura em face dos contextos macroeconómicos desfavoráveis sobretudo do Brasil e da Argentina. Nas várias entrevistas que realizei em São Paulo (Maio/Junho de 2000 e Junho de 2001) junto de sindicalistas e investigadores, foi possível reforçar a ideia de que a acção da CCSCS foi orientada inicialmente para o combate à dívida externa dos países do Cone Sul, e para uma série de acções de solidariedade laboral pautadas por objectivos como a defesa da democracia e dos direitos humanos, e a luta contra os regimes autoritários que ainda subsistiam na região, como eram os casos do Chile e do Paraguai (CCSCS, 2000a: 1). Nestes termos, o tema da integração regional aparecia em segundo plano.

A segunda fase situou-se entre 1991 e 1992. A data da constituição do MERCOSUL - com a assinatura do Tratado de Assunção - representou o ponto de viragem para um reconhecimento do tema da integração regional como central à coordenação entre as centrais sindicais da CCSCS. Nesta fase iniciou-se de forma progressiva a participação institucional das centrais sindicais nas instâncias sociais do MERCOSUL, na altura sobretudo por via da actuação junto do Subgrupo 11. Além disso, a CCSCS foi-se batendo pela constituição de uma Carta Social para o MERCOSUL, baseada

UE como no MERCOSUL as organizações sindicais terem sido claramente relegadas para um segundo plano quanto à sua capacidade para influenciarem os processos de integração regional, não deixa de ser curioso que a CCSCS tenha antecedido a criação do MERCOSUL, ao passo que a sua "equivalente funcional" na Europa, a CES, foi constituída quase duas décadas após o nascimento da Comunidade Económica Europeia, o que poderá ser visto como um sinal de vitalidade do sindicalismo sul-americano. 
quer nas convenções da OIT, quer nalguns aspectos da Carta Social Europeia e composta por "um conjunto de normas laborais e sociais que garantisse iguais direitos e condições de trabalho a todos os trabalhadores dos quatro países" (CUT/CSN, 2000: 52).

A terceira fase, entre 1993 e 1998, ficou marcada por um maior dinamismo das centrais sindicais. Neste espaço temporal, a acção sindical, em especial protagonizada pela CUT brasileira e pelo Plenário Intersindical de Trabalhadores-Central Nacional de Trabalhadores (PIT-CNT) do Uruguai, revelou-se mais activa, tendo as centrais sindicais dos quatro países do MERCOSUL passado a "disputar abertamente espaços no processo de negociação” (Vigevani e Mariano, 1998: 86). Nos anos de 1993 e 1994, por exemplo, as centrais sindicais da CCSCS passaram a ocupar-se de novos temas até então marginais à sua agenda: análise do papel das políticas produtivas (industrial e comercial) e da política de comércio exterior não só em cada um dos países como no próprio bloco. Foi também incentivada a criação de Comissões Sindicais Sectoriais (destinadas a criar condições ao tratamento de temas específicos e a abrir caminho para futuras negociações colectivas por sector ou empresa) e foram feitas reivindicações: adopção imediata de uma Carta dos Direitos Fundamentais dos Trabalhadores; a regulação das negociações por empresa ou sector a uma escala regional; a criação de comissões de empresa multinacionais e o direito de organização e filiação sindical; a realização de diagnósticos destinados a avaliar o grau de integração propiciado pelo emprego e a qualificação da mão de obra, etc. Nos anos de 1997 e 1998, a CCSCS estimulou de novo o funcionamento das referidas Comissões Sindicais Sectoriais, através da realização de encontros dos trabalhadores da indústria do MERCOSUL, e apoiou a formação de uma Comissão de Mulheres destinada a discutir temas interligados com o MERCOSUL (CUT/CSN, 2000: 54-57).

Em meu entender, a participação sindical no MERCOSUL atravessa neste momento uma quarta fase. Trata-se de uma fase iniciada em Janeiro de 1999, com um período de maior instabilidade económica e de desvalorização do "Real”, de resto "já latente nos modelos de estabilização e reestruturação económica especialmente de Brasil e Argentina” (CUT/CSN, 2000: 6). Este cenário adverso veio afectar também as próprias iniciativas sindicais. $\mathrm{Na}$ opinião da CUT (2000: 1, 2001: 10-11), a debilidade crescente das representações nacionais - afectada quer pela intensificação da reestruturação produtiva, quer pela flexibilização das normas laborais, quer pelo crescimento do desemprego, quer ainda pela diminuição da capacidade negocial dos governos - permite observar no MERCOSUL, depois de uma fase inicial mais promissora, um "período de refluxo". 
No entanto, algumas mobilizações colectivas como o Primeiro de Maio de 1999 (na fronteira entre Brasil e Uruguai, em Santana do Livramento e Rivera) e os Encontros Sindicais do MERCOSUL - em Montevideu (Dezembro de 1999), Florianópolis (Dezembro de 2000) e Buenos Aires (Dezembro de 2001), que reuniram, cada um deles, cerca de meio milhar de sindicalistas de diferentes sectores profissionais - tornam provavelmente menos ajustado o uso da expressão "refluxo". Numa declaração apresentada no II Encontro Sindical do MERCOSUL, a CCSCS apelava aos governos do MERCOSUL para adoptarem medidas visando a promoção do emprego, a melhoria dos salários e a protecção social: "Nós estamos cada vez mais conscientes que para solucionar o problema da exclusão social é preciso mudar radicalmente as orientações dos modelos económicos que hoje dirigem nossos países. E para estabelecer bases soberanas de inserção internacional é exigência fortalecer o MERCOSUL através da adopção de políticas de desenvolvimento produtivo e social" (CCSCS, 2000b: 2). Uma orientação neste sentido seria reiterada no III Encontro Sindical do MERCOSUL. Aí a CCSCS apresentou propostas no sentido de criar um "outro MERCOSUL com empregos para todos" (CCSCS, 2001). Ao fazê-lo, criou em seu redor um verdadeiro espaço público de crítica ao MERCOSUL (Barbiero e Chaloult, 2001: 10) e reuniu propostas concretas para a superação do seu impasse.

Assim, não obstante o momento de grande instabilidade por que passa o MERCOSUL, agravado pela situação de ruptura política, económica e social vivida pela Argentina desde Dezembro de 2001, considero preferível, em vez de refluxo, falar numa fase de ambiguidade. Esta fase é, em meu entender, o reflexo de uma atitude sindical perante a integração regional que se caracteriza por um misto de crítica e de aceitação e que foi patente não só no período mais recente de agravamento da instabilidade do MERCOSUL, como também na fase em que a união aduaneira mais avanços logrou alcançar (na segunda metade dos anos 90). Como defendem Barbiero e Chaloult, as centrais sindicais do Cone Sul revelam uma posição sindical ambígua face à regionalização, pois, apesar de alertarem para os perigos que lhes estão associados (nomeadamente, a perda de direitos laborais e de níveis de emprego), acabam por ter como política "defender o MERCOSUL" (1999: 7), o que também é revelador de que há sinais de esperança na construção de um processo mais democrático. Ou seja, "embora se reafirme que a condução do processo de integração é 'inaceitável' para os trabalhadores por privilegiar os interesses empresariais, o movimento sindical no MERCOSUL não assumiu uma posição de repúdio e desconsideração ao processo em andamento" (Veiga, 1999: 189). Um factor que pode reforçar 
esta ideia resulta do facto de a construção institucional gizada neste espaço regional ter vindo a compensar as posições distintas sustentadas pelas centrais sindicais brasileiras, argentinas, uruguaias e paraguaias à escala nacional, em nome de uma estratégia transnacional de "negociação flexível" (Barbiero e Chaloult, 1999: 11, 4). Se, no caso europeu, "os sindicatos passaram mais de duas décadas denunciando a integração regional como obra 'burguesa'” (CUT/CSN, 2000:5), no MERCOSUL essa posição crítica é também uma realidade, ainda que pareça misturar-se com uma atitude de apoio e de colaboração, o que me leva a admitir que o sindicalismo no MERCOSUL se encontra a meio caminho entre uma crítica colaboracionista e um colaboracionismo crítico.

No futuro, a evolução e eventual superação da actual fase de ambiguidade sindical face ao MERCOSUL dependerão certamente da multiplicação de acções transnacionais conjuntas, da assunção de posições comuns perante a evolução da ALCA e, sobretudo, do reforço da discussão/confronto nacional com outros actores, nomeadamente políticos (governos) e económicos (empresários) face a essa questão. Como se deduz das palavras de Sílvia Portella de Castro, a capacidade de acção e intervenção conjuntas nos fora inter-governamentais regionais (na área laboral, das políticas produtivas e do aprofundamento da estrutura institucional) carece de ser complementada no plano local, onde existem "pouquíssimas acções políticas capazes de pressionar as empresas a compensarem ou negociarem as mudanças resultantes dos impactos directos do MERCOSUL" (Castro, 1999a: 69, 2000: 134). Tendo presentes estas contradições, o dilema entre o alargamento da área geográfica do MERCOSUL e o aprofundamento da convergência das matérias e políticas colectivas entre países membros (re)adquire grande actualidade (Peña, 1999). Este dilema condiciona também a evolução das práticas sindicais, estando estas colocadas perante a necessidade de encontrar um equilíbrio entre as duas opções para que aquele dilema aponta. De momento, o aprofundamento afigura-se como a opção mais prioritária para o MERCOSUL, pois a sua consolidação enquanto bloco encontra-se dependente da implementação de políticas macroeconómicas comuns entre os seus países membros e do reforço da sua estrutura institucional. Isso mesmo ficou patente, aliás, no decorrer do III Encontro Sindical do MERCOSUL, realizado em Dezembro de 2001, em Buenos Aires. Nesse Encontro, "o aprofundamento do processo de integração, o fortalecimento da sua estrutura institucional e a adopção de medidas imediatas que contemplem o desenvolvimento produtivo e social" (CCSCS, 2001: 1) foi a nota dominante. Esta necessidade de reforçar a lógica da integração sindical e apelar ao envolvimento de organizações sindicais nesse processo tem vindo, 
inclusive, a ser objecto de actuação sindical conjunta entre o MERCOSUL e a Comunidade Andina (CAN, constituída em 1996, e composta pela Bolívia, Colômbia, Equador, Peru e Venezuela). ${ }^{10}$

Mas se é certo que essas acções conjuntas entre organizações sindicais de blocos regionais distintos reforçam a necessidade de aprofundamento dos respectivos blocos em que elas se inserem, as questões referentes ao alargamento também não devem ser totalmente descuradas. Daí a necessidade, como disse, de ir ao encontro de um equilíbrio entre o aprofundamento e o alargamento. Ainda no caso do MERCOSUL, questões que directamente apenas pareçam dizer respeito ao alargamento da sua área geográfica, como a entrada de novos países para o bloco, não poderão ser equacionadas também sem uma percepção do tipo de políticas macroeconómicas defendidas por esses países, o que significa ir ao encontro da discussão de estratégias de aproximação entre países membros e países candidatos. ${ }^{11}$

\section{Possibilidades para a acção sindical na UE e MERCOSUL}

Apesar de o levantamento de possibilidades de acção sindical nos remeter para desafios de concretização por vezes incerta, o espaço para a sua formulação é tão necessário quanto inevitável, pois destina-se, em muitas situações, a superar obstáculos.

\footnotetext{
${ }^{10}$ Exemplo dessa acção conjunta foi a Declaração Sindical entre o MERCOSUL e a CAN, subscrita em 31 de Agosto de 2000 pelas centrais sindicais de ambos os blocos, e visando o "aprofundamento da integração e formação de um bloco para a defesa dos direitos e do desenvolvimento social" (CCSCS et al., 2000: 1). Discordando da política excessivamente subordinada à lógica do livre mercado que tem guiado as negociações no MERCOSUL e na CAN e entre ambas as sub-regiões, as centrais sindicais batem-se pela "integração física das vias de comunicação, de energia e telefonia", o que significa a "adopção de políticas comuns de promoção produtiva, de tributação e taxas fiscais (impedir que as grandes empresas multinacionais utilizem a guerra fiscal como arma de chantagem como vêm fazendo) e principalmente a decisão de adoptar como prioridade o tratamento da dimensão social de que este processo se reveste" (CCSCS et al., 2000: 2). O diálogo sindical entre MERCOSUL e CA tem, entretanto, vindo a prosseguir, com o ficou expresso no III Encontro Sindical entre ambos os blocos realizado em Setembro de 2001 (Correio Sindical Mercosul,2001b: 1). ${ }^{11}$ Depois de muito se ter anunciado a adesão do Chile ao MERCOSUL, a negociação, em Dezembro de 2000, de um tratado de livre comércio entre este país e os EUA terá condicionado a estratégia de alargamento do bloco da América do Sul. Porém, esse facto constituirá também uma chamada de atenção para os problemas de aprofundamento que, neste caso, terão sido causados pela não redução da Tarifa Externa Comum (TEC) - adoptada pelos países membros do MERCOSUL sobre a importação de países terceiros -, situada em torno dos 14\%, e que o Chile pretendia ver reduzida para $9 \%$. Segundo alguns políticos brasileiros do Itamaraty (Ministério dos Negócios Estrangeiros), o distanciamento do Chile inviabilizou o reforço do projecto de mercado comum e fez diminuir o peso do MERCOSUL nas negociações sobre a constituição da ALCA (Correio Sindical Mercosul, 2000a: 8). Resta, pois, aguardar que, por via da actuação sindical, a Central Unitaria de Trabajadores do Chile - que é membro da CCSCS embora o país não seja membro do MERCOSUL - possa continuar o trabalho de cooperação sindical e de actuação conjunta com as demais centrais do Cone Sul, reforçando assim, pelo lado sindical, a lógica de aprofundamento.
} 
No que diz respeito ao caso europeu, as possibilidades de acção sindical estão condicionadas, a meu ver, por dois factores:

Em primeiro lugar, pelo incentivo, no âmbito da CES, a uma gestão mais eficaz das suas diversidades internas. Como assinala Jon Erik Dølvik (2000: $60,64,74)$, as relações de poder desiguais entre organizações membros da CES - como as confederações sindicais nacionais e as federações sindicais europeias (responsáveis pela actuação sindical sectorial) -, para além de constituírem um foco de tensão interna, têm dificultado a intermediação de interesses. Tal incentivo é ainda tanto mais necessário quanto se sabe que persistem, no contexto europeu, diversidades entre o Sul e o Norte sindicais: o Sul, historicamente marcado pela presença de confrontos ideológicos e modelos de sindicalismo mais pluralistas/competitivos; o Norte, caracterizado grosso modo por estruturas sindicais nacionais que agregam em seu redor os interesses sindicais de um modo mais uniforme. Além disso, é bom não esquecer a questão do alargamento sindical a organizações provenientes dos países de Leste. Este desafio do alargamento parece, sem dúvida, fazer mais sentido na UE do que no MERCOSUL, pois naquela, apesar dos obstáculos ainda persistentes a uma União Social, é muito maior o amadurecimento (ou seja, o aprofundamento de que falava atrás) político das instituições. No entanto, também esse desafio requer uma reforma das instituições, precisamente com o objectivo de aumentar a sua eficácia e democracia (CES, 1999: 45-48). E ainda que a paz, os direitos sociais e humanos e a solidariedade sejam, segundo a CES, palavras-chave para legitimar a ideia de alargamento da UE no plano sindical, o desafio da gestão das diversidades entre sindicatos permanece na ordem do dia. Como argumenta Renate Langewiesche (2000: 364), o próximo alargamento da UE transporta consigo importantes diferenças qualitativas e quantitativas relativamente a todos os quatro alargamentos anteriores que tiveram lugar entre 1973 e 1995: nunca houve tantos candidatos à adesão e nunca como agora as diferenças entre os países membros da UE e os candidatos à adesão foi tão evidente. Além disso, nunca as diferenças entre os próprios países candidatos à adesão foram tão grandes como agora. ${ }^{12}$

A segunda possibilidade de acção sindical para o sindicalismo europeu assenta na necessidade de expansão do âmbito da sua cooperação para além do bloco UE. Neste caso, o desafio reside em superar o eurocentrismo

\footnotetext{
12 Para uma síntese dos alargamentos internos da CES, cf. Hoffmann, 2000: 631; para uma discussão da questão do alargamento da UE segundo uma vertente sindical, cf. o número temático da revista Transfer (2000). Consulte-se também, para um acompanhamento das reivindicações e desafios mais importantes que a Europa Social vai enfrentar nos próximos anos, o documento académico “A Manifesto for Social Europe 2000" elaborado por Bercusson et al. (2000).
} 
(Linden, 2000: 538), ainda que a UE se constitua como ponto de partida e espaço que oferece maiores possibilidades de cooperação entre sindicatos do que a escala mundial (Jacobi, 2000: 12, 21, 23; Dølvik, 2000: 73-74). Ou seja, o discurso europeizante protagonizado pela CES e assente na ideia de consolidação do poder sindical europeu deveria ser usado mais como confronto face às estratégias patronais e menos como argumento que pode suscitar colisão com estratégias sindicais de outros blocos regionais. Com efeito, o discurso centrado na valorização da dimensão social da integração europeia e na distinção entre "integração europeia" e "globalização", apesar de legítimo, parece por vezes excessivo, visto que a CES (1999: 19-20) fala num "modelo social de referência" - europeu - como sendo o único passível de dar resposta aos problemas causados aos cidadãos pela globalização. Em resumo, uma flexibilização dos discursos e das práticas seria uma condição importante para que os blocos económicos regionais pudessem cumprir, como referi anteriormente, a função de intermediação entre raizes sindicais nacionais e opções laborais globais. Afinal, a UE e o MERCOSUL aqui em análise situam-se "algures entre a utópica sociedade global e o renascimento do Estado Nação" (Jacobi, 2000: 22), o que permite configurar a integração sindical regional como uma luta pela justiça social situada entre os níveis global e nacional (Dølvik, 2000: 59).

No que diz respeito ao MERCOSUL, considero que as possibilidades de acção sindical se encontram dependentes de três factores:

Em primeiro lugar, a constatação de que a acção sindical é construída como resposta às iniciativas empresariais implica, quase de imediato, uma necessidade de aproximação entre o "económico" e o "social", ainda que a secundarização do "social" se tenha generalizado um pouco por todo o lado. Nesse sentido, um acompanhamento atento, construtivo e crítico das relações comerciais intra-regionais deveria constituir-se como uma prioridade para o sindicalismo do MERCOSUL e, quiçá, com estratégia tendente a reforçar a articulação das práticas sindicais transnacionais no âmbito do bloco. Segundo dados de uma pesquisa conjunta da CUT brasileira e da Confédération des Syndicats Nationaux (CSN) do Canadá (CUT/CSN, 2000: 7), o comércio intra-MERCOSUL aumentou cerca de seis vezes entre 1990 e 1998, embora no ano de 1999 se tenha assistido a uma quebra da $30 \%$ desse comércio. Mesmo que esta quebra acentuada em 1999 tenha servido para confirmar que o "crescimento do comércio intra-regional não tem contrabalançado o crescente déficit comercial externo do MERCOSUL" (Castro, 1999b: 11) e mesmo que o Brasil e Argentina ainda sejam responsáveis por $70 \%$ do comércio intraMERCOSUL (Castro, 1999a: 7) (o que também diz bem da subalternidade 
do Uruguai e do Paraguai), continua a ser indispensável que os sindicatos do MERCOSUL atribuam uma atenção crescente ao comércio intra-bloco, sobretudo pelas mais do que prováveis modificações deste estado de coisas que decorrerão do agravamento da crise argentina. Registe-se, por exemplo, que o sindicalismo europeu protagonizado pela CES valoriza precisamente o facto de na Europa se consumir cerca de $90 \%$ do que lá se produz, o que tem sido claramente apropriado como factor de força negocial pelo próprio sindicalismo europeu.

Um segundo factor que constitui, em meu entender, uma possibilidade de acção sindical para o MERCOSUL está directamente relacionado com o primeiro, pois a dinamização das trocas comerciais intra-bloco desafiará certamente o sindicalismo do MERCOSUL, inserido na CCSCS, a reforçar a sua intervenção e participação no âmbito da Organização Regional Interamericana dos Trabalhadores (ORIT) ${ }^{13}$, e a criar um estímulo para que esta olhe com mais atenção para o MERCOSUL ${ }^{14}$. Neste sentido, é indispensável um grande trabalho de cooperação entre as centrais sindicais do Cone Sul e a ORIT. A CUT brasileira, conjuntamente com outras estruturas sindicais (como a CLC do Canadá e a AFL-CIO dos EUA), têm vindo a desempenhar um papel importante de descentralização da ORIT, tendo mesmo proposto no XIV Congresso desta organização, em 1997, a criação de secretários-gerais adjuntos com capacidades de intervenção temática. Como me dizia um ex-assessor de política internacional da CUT, "antes a figura do secretário-geral estava isolada, e essa é uma mudança que descentraliza $[\ldots]$ e permite ter uma presença mais regional, sendo também esses secretários oriundos de distintas regiões do Continente" (entrevista, Junho de 2000). Para que as afinidades inter-sindicais em redor da integração sindical não esmoreçam, é, pois, desejável a promoção, através da CCSCS e da ORIT, do intercâmbio "com centrais e confederações do Nafta, do Caribe, do Pacto Andino e da América Central sobre os temas da integração e envolvendo as nossas estruturas verticais" (CUT, 1997: 5).

O terceiro factor que poderá reforçar a acção sindical no MERCOSUL é a intensificação dos processos de diálogo e cooperação entre o sindicalismo e outras organizações da sociedade civil. A primeira resolução conjunta, celebrada em 1997, entre a ORIT e organizações da sociedade civil visando a constituição de uma "Aliança Social Continental" face ao livre comércio

\footnotetext{
13 A ORIT, fundada em 1951, constitui uma organização regional da CISL para as Américas. Historicamente, foi instrumentalizada pelo sindicalismo americano protagonizado pela American Federation of Labor-Congress of Industrial Organizations (AFL-CIO) (Stevis, 1998: 14; Jakobsen, 1998: 307), sobretudo porque esta organização pretendia impedir o avanço do comunismo no hemisfério americano e, em especial, na América Latina.
} 
deve ser vista como um ponto de partida e não como um ponto de chegada, fazendo com que este debate sobre a relação entre o sindicalismo e outras organizações não sindicais da sociedade civil conste da agenda do sindicalistas nos espaços nacionais e locais de intervenção. Apesar das dificuldades existentes, tal debate deveria ser aprofundado dentro da CCSCS. Não se trata de confundir papéis ou atribuições, mas tão-só de incentivar o sindicalismo do MERCOSUL a proceder a uma renovada visão do mundo e dos seus problemas que não esteja exclusivamente assente em interesses sindicais. Talvez por, historicamente, os sindicatos se encontrarem mais presos a um registo de actuação formal e institucionalizado (por vezes mesmo burocrático), devessem ser eles mesmos a tomar a iniciativa de dialogar com as organizações da sociedade civil. Reclama-se, pois, uma atitude propositiva em vez de uma atitude meramente reactiva. A "Rede Brasileira pela Integração dos Povos", que reafirma o compromisso em favor da construção da referida aliança social continental deve, assim, ser levada por diante, pois a "sua riqueza reside precisamente na diversidade de temas e enfoques para tratar das questões excluídas dos acordos oficiais" (CUT/ CFTD, 1999: 2). Aliás, por ocasião do II Encontro Sindical do MERCOSUL (Dezembro de 2000), o apelo ao diálogo com as organizações mais representativas da sociedade civil e ao fortalecimento das organizações sociais no FCES do MERCOSUL foi uma vez mais lembrado (CCSCS, 2000b: 2). Como demonstram alguns artigos deste número temático (nomeadamente os textos de Richard Hyman, Peter Waterman e Roberto Véras), este desafio da articulação e actuação conjunta entre sindicatos e outras organizações que lutam pela emancipação social assume-se cada vez mais como uma exigência não só para a Europa e América do Sul mas para o mundo inteiro. As duas edições do Fórum Social Mundial (realizadas em Porto Alegre, respectivamente em Janeiro de 2001 e Janeiro de 2002) são a expressão porventura mais acabada de que alianças sociais de âmbito mundial vão ganhando forma de dia para dia.

São, pois, amplas as possibilidades de acção sindical tanto na UE como no MERCOSUL. Por outro lado, nos desafios de cooperação sindical conjunta entre os dois blocos regionais residem novas esperanças de intervenção à escala regional. O Comunicado Conjunto (redigido em 6 de Setembro de 2001) pela CES, CCSCS e pelo Consejo de Trabajadores del Cono

\footnotetext{
${ }^{14}$ Segundo apurei nalgumas entrevistas que realizei em São Paulo junto de sindicalistas da CUT brasileira e do PIT-CNT do Uruguai, a ORIT, não obstante ter apoiado a constituição da CCSCS, tem prestado pouca atenção à evolução do MERCOSUL, o que pode ser visto como um factor inibidor de protagonismo sindical transnacional. Para uma análise de algumas sugestões quanto à actuação futura da ORIT, cf. Jakobsen, 1998: 315-317, 2001: 73-77.
} 
Sur (CTCS $)^{15}$, destinado a acompanhar as negociações que desde 1999 se desenvolvem entre a UE e o MERCOSUL (mais o Chile) para a obtenção de um acordo de livre comércio entre os dois blocos (com data prevista de início para 2005), é um exemplo disso, indo mesmo para além do MERCOSUL. Nessa declaração conjunta, a CES, CCSCS e CTCS acordaram, entre outros pontos: fazer assentar as relações entre as estruturas sindicais do Cone Sul e da UE em "princípios de reciprocidade, autonomia, cooperação e solidariedade"; não fazer restrições quando à discussão de sectores económicos; incluir nesse acordo um "capítulo específico sobre a defesa e respeito dos direitos laborais" (CES/CTCS/CCSCS, 2001: 1). Na sequência desse Comunicado Conjunto, um Seminário sobre a participação sindical nas negociações entre UE e MERCOSUL seria organizado pelas mesmas organizações (Buenos Aires, 9 e 10 de Abril de 2002). Nele, CES, CTCS e CCSCS reiteraram a necessidade salvaguardar a dimensão social num futuro acordo de associação bi-regional entre os dois blocos. A aprovação das propostas de inclusão de um capítulo sócio-laboral específico de protecção dos direitos laborais, de constituição de um Fórum Sindical UE-MERCOSUL (à semelhança do já existente Fórum Empresarial), ou da salvaguarda das negociações colectivas, nomeadamente através da criação de Conselhos de Empresa bi-regionais, foram as principais linhas de força saídas desse Seminário (CES/CTCS/CCSCS: 2002: 2-3).

\section{Contributos para um sindicalismo de língua portuguesa}

É no quadro de posições conjuntas como a que acabei de citar que poderão, inclusive, vir a fortalecer-se as relações entre organizações sindicais de países da UE e MERCOSUL. Estou a pensar, em concreto, no reforço das possibilidades de cooperação sindical entre países (como Portugal e o Brasil) que, nos dois blocos, falam a língua portuguesa. Embora tenha alertado inicialmente para o distinto peso económico de Portugal e do Brasil nos blocos económicos regionais em que se inserem, considero não existir uma relação directa entre a força/fraqueza económica de um país e a sua força/ fraqueza sindical, facto que, por si só, tornaria politicamente precipitado rotular de "Norte do Sul" o sindicalismo brasileiro e de "Sul do Norte" o sindicalismo português.

A investigação que venho realizando sobre a transnacionalização do sindicalismo nos dois países permitiu-me constatar, todavia, que um

15 Do mesmo modo que a CCSCS é apoiada pela CISL e pela ORIT, o CTCS é uma estrutura sindical pertencente à Confederação Mundial do Trabalho (CMT) e à sua estrutura regional para a América Latina, a Central Latino-Americana de Trabalhadores (CLAT). 
"sindicalismo de língua portuguesa", resultante do intercâmbio entre organizações sindicais portuguesas e brasileiras, é bastante deficitário. Não pretendo, aqui, discutir as razões para tal desinteresse e desconhecimento recíprocos, ainda que as diferenças no modo como se processaram as mudanças na legislação laboral na sequência das transições das ditaduras para as democracias, ou a forma como, genericamente, a organização sindical está estruturada nos dois países, pudessem servir como interpretação imediatista para justificar semelhante distanciamento. Os responsáveis sindicais portugueses e brasileiros reconhecem, no entanto, que é desejável uma aproximação entre ambos os movimentos sindicais, não obstante poderem subsistir diferenças ideológicas internas em cada um deles ou mesmo entre ambos. Por forma a contribuir para essas intenções de aproximação, proponho que se tenham em consideração duas possibilidades interligadas de cooperação sindical em língua portuguesa.

Uma primeira possibilidade de reforçar a cooperação sindical entre Portugal e o Brasil passaria por um maior empenho e participação das centrais sindicais de ambos os países em iniciativas como a Comunidade Sindical dos Países de Língua Portuguesa (CPLP Sindical). Esta iniciativa, nascida em Maio de 1998, envolve as 13 mais importantes centrais sindicais dos 7 países que fazem parte da Comunidade de Países de Língua Oficial Portuguesa, e os objectivos para que foi criada incluem, nomeadamente: a defesa da democracia, da promoção do desenvolvimento económico e social e da melhoria das condições de vida e de trabalho; a reivindicação de uma melhor legislação económica e social; o apoio aos trabalhadores imigrantes; a promoção de processos de formação inicial e contínua dos trabalhadores; o estímulo à acção internacional. Porém, segundo vários líderes sindicais que entrevistei em Portugal e no Brasil, as iniciativas realizadas no âmbito da CPLP Sindical encontram-se adormecidas. Seria, pois, bastante positivo que as organizações sindicais brasileiras e portuguesas dinamizassem a sua reactivação, em abono de uma eficaz aplicação dos estatutos e programa de acção da CPLP Sindical. ${ }^{16}$ Convénios de cooperação entre os dois países, como o que ficou acordado em Setembro de 2000 entre a secção brasileira do Fórum Consultivo Económico e Social (FCES) e o Conselho Económico e Social Português (CES-P) - nos termos do qual se prevê "um intercâmbio de informações e experiências sobre vários aspectos dos processos de integração e uma iniciativa conjunta dos dois organismos para o desenvolvimento de um programa de cooperação com os países africanos de lín-

\footnotetext{
${ }^{16}$ Para um breve comentário das principais organizações sindicais portuguesas sobre este assunto, cf. CGTP, 1999: 50; UGT, 2000: 118.
} 
gua portuguesa" (Correio Sindical Mercosul, 2000b: 7) - constituem um estimulante instrumento de reactivação da cooperação sindical mesmo que não se reduzam unicamente a interesses sindicais.

Uma segunda possibilidade de cooperação sindical em língua portuguesa prende-se com a necessidade de promover processos de aprendizagem recíproca entre Portugal e o Brasil. A meu ver, isso poderia ser feito de duas formas. Por um lado, pela identificação e valorização de semelhanças ao nível da realidade laboral/sindical em ambos os países, das quais destacaria as seguintes: a tradição autoritária por que passaram ambos os movimentos sindicais; uma bipolarização sindical ao nível do topo; a crise de representatividade do sindicalismo (declínio da sindicalização); o espaço restrito concedido à acção sindical internacional; a existência de estruturas sindicais pouco rejuvenescidas; uma acção sindical centrada em temas nacionais comuns aos mercados de trabalho dos dois países (luta contra o desemprego; a necessidade de qualificar os trabalhadores e o emprego; a atenção crescente às formas atípicas de emprego; etc.).

Uma segunda forma de fomentar uma aprendizagem recíproca entre ambos os sindicalismos passaria pela concessão de uma atenção especial às "forças" do "outro sindical". Neste sentido, o sindicalismo português poderia aprender com o brasileiro a: valorizar e dinamizar mais "experiências de base"; conceder um espaço mais amplo ao debate de ideias com outras organizações não sindicais da sociedade civil; estimular uma abertura do movimento sindical à cooperação com universidades e centros de investigação. Por outro lado, e não obstante a fraca europeização da negociação colectiva portuguesa (Naumann, 2000:381), o sindicalismo brasileiro poderia aprender com o sindicalismo português o modo como este se vem progressivamente articulando e participando em instâncias sociais europeias há mais tempo consolidadas, como a CES, as FSEs, o Comité Económico e Social da UE (CES-UE), ou mesmo a OIT, sediada na Europa. Tratar-se-ia, por certo, de uma referência útil para a actuação do sindicalismo brasileiro no quadro de instâncias sociais mais recentemente constituídas no âmbito do MERCOSUL, como a CCSCS, o Subgrupo 10 (assuntos trabalhistas, emprego e segurança social) ou o FCES.

\section{Conclusão}

O MERCOSUL espelha, certamente melhor do que a UE, as dificuldades da integração regional. Em dez anos de existência, "conseguiu aumentar o comércio intra-regional e criar complementaridades entre os países membros, mas falhou redondamente no sentido de estabelecer estruturas institucionais. Por outro lado, consolidou o regime democrático como 
padrão absoluto de inclusividade no bloco comercial e criou uma dinâmica de posições comuns em negociações com terceiros países e em foruns internacionais" (Brito e Migueis, 2002: 28). Não espantará, pois, que o caminho a percorrer pelo sindicalismo do MERCOSUL seja mais longo do que aquele que os sindicatos europeus têm pela frente. Para os mais pessimistas, o MERCOSUL estará mesmo num beco sem saída, sobretudo depois de a III Cimeira Presidencial das Américas (Quebec, Abril de 2001) ter confirmado a ALCA para 2005. Como se isso não bastasse, em Dezembro de 2001, para além da agudização da crise argentina (que constitui, afinal, o epicentro da crise do MERCOSUL), o presidente americano George W. Bush viu aprovado na Câmara dos Deputados um projecto de lei que o autoriza a negociar acordos comerciais sem interferência do Congresso, a chamada Trade Promotion Authority.

Se é certo que estes factos estimulam o sindicalismo a reforçar a sua busca de unidade à escala regional, por outro lado, eles revelam também que o sindicalismo do MERCOSUL tem ainda, como dizia, um longo caminho a desbravar. A síntese das principais etapas do "social" em ambos os blocos não escondeu, também ela, a existência de timings diferenciados entre a UE e o MERCOSUL. Não obstante isso, as organizações sindicais de ambos os blocos partilham algumas dificuldades que são, em grande medida, decorrentes dos desafios suscitados pela mudança da escala de intervenção sindical do plano nacional para o plano transnacional.

Grosso modo, as possibilidades de actuação sindical na UE e MERCOSUL aqui sugeridas convocam-nos, quer para um aprofundamento das formas de convergência sindical nesses blocos, quer para um alargamento dos horizontes de intervenção do sindicalismo, indo ao encontro de debates e problemas mais amplos que não passem exclusivamente por preocupações sindicais. É ainda de admitir que a eficácia de tais propostas de actuação sindical no quadro da integração regional possa sair reforçada com uma maior aproximação entre as organizações sindicais que representam os dois blocos regionais, na linha de algumas posições conjuntas já assumidas. Sem que, uma vez mais, deva esquecer-se que existem diferenças de interesses entre as organizações sindicais do MERCOSUL e da UE, seria, no entanto, desejável, seguindo as sugestões de Maria Sílvia Portella de Castro (1999b: 27): uma multiplicação de acções de solidariedade para com as principais lutas sindicais em cada região; um acompanhamento sindical atento das negociações económicas, comerciais e políticas entre a UE e o MERCOSUL/América Latina; uma articulação entre sindicatos e representantes sindicais de ambos os blocos em empresas multinacionais situadas nas duas regiões. Experiências como a dos Conselhos de Empresa Europeus 
- constituídos a partir da UE - poderiam servir de pretexto para a realização de acções sindicais conjuntas e para a luta por direitos laborais nos locais de trabalho numa base ainda mais alargada. Por sua vez, conviria não esquecer que a cooperação sindical numa base transnacional estimula a promoção de formas de aprendizagem recíproca entre países. Nesse sentido, aos sindicatos portugueses e brasileiros recomendar-se-ia uma maior aproximação a um sindicalismo de língua portuguesa, pois daí resultaria também uma acrescida convergência entre a UE e o MERCOSUL.

\section{Siglas}

AFL-CIO, American Federation of Labor-Congress of Industrial Organizations

ALCA, Área de Livre Comércio das Américas

CAN, Comunidade Andina

CCSCS, Coordenadora de Centrais Sindicais do Cone Sul

CEEs, Conselhos de Empresa Europeus

CES, Confederação Europeia de Sindicatos

CES-P, Conselho Económico e Social de Portugal

CES-UE, Comité Económico e Social da União Europeia

CGT, Confédération Générale du Travail

CGTP, Confederação Geral dos Trabalhadores Portugueses

CISL, Confederação Internacional dos Sindicatos Livres

CLAT, Central Latino-Americana de Trabalhadores

CMT, Confederação Mundial do Trabalho

CPLP Sindical, Comunidade Sindical dos Países de Língua Portuguesa

CSN, Confédération des Syndicats Nationaux

CTCS, Consejo de Trabajadores del Cono Sur

CUT, Central Única dos Trabalhadores

DGB, Deutscher Gewerkschaftsbund

FCES, Fórum Consultivo Económico-Social

FSEs, Federações Sindicais Europeias

FSM, Federação Sindical Mundial

MERCOSUL, Mercado Comum do Sul

NAFTA, North American Free Trade Agreement

OIT, Organização Internacional do Trabalho

ORIT, Organização Regional Interamericana dos Trabalhadores

PIT-CNT, Plenário Intersindical de Trabalhadores - Central Nacional de Trabalhadores

TEC, Tarifa Externa Comum

TUC, Trade Unions Congress

UE, União Europeia

UGT, União Geral de Trabalhadores 


\section{Referências Bibliográficas}

Barbiero, Alan; Chaloult, Yves (1999), "Desafios, estratégias e alianças das centrais sindicais no Mercosul". <http://www.sol.unb.br/yves/astalanyves10.html>, acedido em 19.11.1999.

Barbiero, Alan; Chaloult, Yves (2001), "O défice democrático do MERCOSUL". <http:/ www.sol.unb.br/yves/Artigos\%20Deficit.html>, acedido em 11.07.2001.

Bercusson, Brian et al. (2000), "A Manifesto for Social Europe 2000", Transfer - European Review of Labour and Research, 6(3), 498-513.

Brito, Alexandra Barahona de; Migueis, Ricardo (2002), “América Latina: Uma curva descendente?”, O Mundo em Português, 28, 25-28.

Castro, Maria Sílvia Portella de (1999a), "Mercosul e relações trabalhistas", Informe para a OIT sobre integração económica e relações trabalhistas (policopiado), 1-72.

Castro, Maria Sílvia Portella de (1999b), "Elementos para a análise das relações económicas e políticas entre a União Europeia e o Mercosul e as propostas sindicais", Paper para discussão da CCSCS (policopiado), 1-28.

Castro, Maria Sílvia Portella de (2000), "Movimento Sindical no Mercosul: trajectória e perspectivas de acção”, in J. Lorenzetti; O. L. Faccio (orgs.), O Sindicalismo na Europa, Mercosul e Nafta. São Paulo: Ltr/Escola Sul da CUT, 103-135.

CCSCS (2000a), "Documentos: Coordenadora das Centrais Sindicais do Cone Sul". $<$ http://www.sincatomercosul.com.br/document.htm\#parte2>, acedido em 3.01.2001.

CCSCS (2000b), "Por um Mercosul com emprego, salários e protecção social (bilingue)". $<$ http://www.sindicatomercosul.com.br/noticias.asp?numero=472>, acedido em 3.01.2001.

CCSCS (2001), Por otro MERCOSUR con empleo para todos. III Cumbre Sindical MERCOSUR (Anexo ao Correio Sindical Mercosul, 97).

CCSCS et al. (2000), "Declaração Sindical Mercosul - CA: Integração com desenvolvimento social, soberania e democracia". <http://www.sindicatomercosul.com.br/ documen13.htm>, acedido em 3.01.2001.

CES (1999), Résolutions. IXème Congrès. Bruxelles: CES.

CES/CTCS/CCSCS (2001), "Comunicado conjunto de la Coordinadora de Centrales Sindicales del Cono Sur (CCSCS), Consejo de Trabajadores del Cono Sur (CTCS) y la Confederación Europea de Sindicatos (CES)", Correio Sindical Mercosul, 84, 2. CES/CTCS/CCSCS (2002), Las negociaciones Unión Europea-Mercosur, y la participatición sindical. Declaración final. (Anexo ao Correio Sindical Mercosul, 107), 1-3.

CGTP (1999), Relatório de Actividades do IX Congresso. Lisboa: CGTP.

Chaloult, Yves; Almeida, Paulo Roberto (1999), "Apresentação", in Chaloult e Almeida (orgs.), 7-14.

Chaloult, Yves; Almeida, Paulo Roberto (orgs.) (1999), Mercosul, Nafta e Alca: A dimensão social. São Paulo: Ltr. 
Correio Sindical Mercosul, (2000a), 57, 4 de Dezembro (recebido electronicamente via cesint@uol.com.br.)

Correio Sindical Mercosul, (2000b), 58, 10 de Dezembro (recebido electronicamente via cesint@uol.com.br.)

Correio Sindical Mercosul, (2001a), 85, 17 de Setembro (recebido electronicamente via cesint@uol.com.br.)

Correio Sindical Mercosul, (2001b), 84, 10 de Setembro (recebido electronicamente via cesint@uol.com.br.)

Correio Sindical Mercosul, (2001c), 97, 16 de Dezembro (recebido electronicamente via cesint@uol.com.br.)

Costa, Hermes Augusto (2000), "Identidades sindicais europeias em tempos de globalização”, Tempo Social, 12(1), 165-186.

Costa, Hermes Augusto (2001), "Sindicalismo e integração regional: Uma visão sobre Portugal e o Brasil", Sociologia, Problemas e Práticas, 36, 121-142.

CPLP Sindical (1998), Brochura com declaração de constituição, estatutos e programa de Acção. Lisboa: CPLP Sindical.

CUT (1997), "Directrizes de Actuação Internacional CUT, 1997-2000". <http:// www.cut.org.br/a1001.htm>, acedido em 28.04.2000.

CUT (2000), "Sindicatos buscam unidade no Mercosul”, Boletim Mercosul, 18, 1-8.

CUT (2001), Resoluções e Imagens do $7^{\circ}$ CONCUT. São Paulo: CUT.

CUT/CFDT (1999), "Alternativas para as Américas: para um acordo dos povos do continente”, Textos para debate internacional, 13, 1-60.

CUT/CSN (2000), Integração regional, mercado de trabalbo e acção sindical: $O$ caso Mercosul (versão preliminar). São Paulo: DESEP; SRI/CUT (policopiado).

Dølvik, Jon Erik (2000), "Building Regional Structures: ETUC and the European Industry Federations”, Transfer - European Review of Labour and Research, 6(1), 58-77.

Dupas, Gilberto (1999), "Governos, agentes económicos e atores sociais: Riscos e desafios da globalização e da política de blocos”, in Chaloult e Almeida (orgs.), 132-146.

ETUC (2002), “About ETUC”. <http://www.etuc.org/en/about_etuc/>, acedido em 5.02.2002.

Goetschy, Janine (1996), “The European Trade Union Confederation and the Construction of European Unionism”, in P. Leisink; J. Van Leemput; J. Vilrokx (orgs.), The Challenges to Trade Unions in Europe: Innovation or Adaptation. Cheltenham: Edward Elgar, 253-265.

Hoffmann, Reiner (2000), "European Trade Union Structures and the Prospects for Labour Relations in Europe”, in J. Waddington; R. Hoffmann (orgs.), Trade Unions in Europe: Facing Challenges and Searching for Solutions. Brussels: ETUI, 627-653. 
Hyman, Richard (1996), "Changing Union Identities in Europe”, in P. Leisink; J. Van Leemput; J. Vilrokx (orgs.), The Challenges to Trade Unions in Europe: Innovation or Adaptation. Cheltenham: Edward Elgar, 53-73.

Hyman, Richard (1999), "Five Alternative Scenarios for West European Unionism", in R. Munk; P. Waterman (orgs.), Labour Worldwide in the Era of Globalization: Alternative Union Models in the New World Order. London: MacMillan Press.

Jacobi, Otto (2000), "Transnational Trade Union Cooperation at Global and European Level - Opportunities and Obstacles”, Transfer-European Review of Labour and Research, 6(1), 12-28.

Jakobsen, Kjeld (1998), “Nuevos rumbos en la ORIT?”, in M. S. P. Castro; A. Wachendorfer (orgs.), Sindicalismo y globalización: La dolorosa inserción en un mundo incierto. Caracas: Editorial Nueva Sociedad, 307-318.

Jakobsen, Kjeld (1999), "Uma visão sindical em face da ALCA e de outros esquemas sindicais”, in Chaloult e Almeida (orgs.), 232-248.

Jakobsen, Kjeld (2001), "Rethinking the International Confederation of Free Trade Unions and its Inter-American Regional Organization”, in P. Waterman; J. Wills (orgs.), Place, Space and the New Labour Internationalisms. Oxford: Blackwell, 59-79.

Langewiesche, Renate (2000), "Editorial”, Transfer - European Review of Labour and Research, 6(3), 364-366.

Linden, Marcel van der (2000), "Conclusion: The Past and the Future of International Trade Unionism”, in A. Carew et al. (orgs.), The International Confederation of Free Trade Unions. Bern: Peter Lang, 519-540.

Naumann, Reinhard (2000), "Portugal”, in G. Fajertag (org.), Collective Bargaining in Western Europe 1998-1999. Bruxelas: European Trade Union Institute, 369-384. Peña, Félix (1999), "Broadening and Deepening: Striking the Right Balance", in R. Roett (org.), Mercosur: Regional Integration, World Markets. London: Lynne Rienner Publishers, 49-61.

Pereira, Lia Valls (1999), “Toward the Common Market of the South: Mercosur's Origins, Evolution, and Challenges”, in R. Roett (org.), Mercosur: Regional Integration, World Markets. London: Lynne Rienner Publishers, 7-23.

Roett, Riordan (1999), "Introduction”, in R. Roett (org.), Mercosur: Regional Integration, World Markets. London: Lynne Rienner Publishers, 1-5.

Sá, Jorge Vasconcellos e; Fraquilho, Miguel; Jorge, Frederico Machado (2001), Portugal Europeu?. Lisboa: Vida Económica.

Santos, Boaventura de Sousa (2000), "Brasília, Portugal”, Visão, 18 de Maio, 54.

Santos, Boaventura de Sousa (2001), "Os processos da globalização”, in B. S. Santos (org.), Globalização: Fatalidade ou utopia?. Porto: Afrontamento, 31-106.

Silva, Manuel Carvalho da (2000a), Acção Sindical: Transformação e desenvolvimento. Porto: Campo das Letras. 
Silva, Manuel Carvalho da (2000b), "Um olhar sobre a evolução da Europa Social", Sociologia, Problemas e Práticas, 32, 55-92.

Silva, Vicente Paulo da (1997), “Globalização”. <http://www.cut.org.br/a20107.htm.>, acedido em 14.06.1999.

Stevis, D. (1998), "International Labor Organizations, 1864-1997: The Weight of History and the Challenges of the Present", Journal of World-Systems Research. <http:// csf.colorado.edu/wsystems/jwsr.html>, 4, 52-75, acedido em 30.09.1999.

Streeck, Wolfgang (1998), “The Internationalization of Industrial Relations in Europe: Prospects and Problems”, Politics E Society, 26(4), 429-459.

Streeck, W.; Schmitter, P. C. (1998), "From National Corporatism to Transnational Pluralism: Organised Interests in the Single European Market, in E. Gabaglio; R. Hoffmann (orgs.), The ETUC in the Mirror of Industrial Relations. Bruxelas: ETUI, 131-170.

Transfer - European Review of Labour and Research (2000), Número temático sobre "Enlargement as a Trade Union Issue", 6(3).

Traxler, Franz; Schmitter, Philippe C. (1995), "The Emerging Euro-Polity and Organized Interests”, European Journal of International Relations, 2(1), 191-218.

UGT (2000), Resolução Programática do VIII Congresso. Lisboa: UGT.

Veiga, João Paulo Cândia (1993), "Mercosul: Evolução institucional e intervenção sindical”, in Projecto IRES/DESEP, Mercosul: Integração na América Latina e relações com a Comunidade Europeia. São Paulo: Cajamar, 197-211.

Veiga, João Paulo Cândia (1999), "Práticas sindicais e acordos preferenciais de comércio: Um novo caminho para o sindicalismo?”, in Chaloult e Almeida (orgs.), 170-189.

Veiga, Pedro Motta da (1999), "Brazil in Mercosur: Reciprocal Influence”, in R. Roett (org.), Mercosur: Regional Integration, World Markets. London: Lynne Rienner Publishers, 25-33.

Vigevani, Tullo (1998), Mercosul: Impactos para trabalbadores e sindicatos. São Paulo: Ltr.

Vigevani, Tullo; Mariano, Karina L. P. (1998), "Os atores sociais e a Alca”, in J. A. G. Albuquerque; H. A. Oliveira (orgs.), Alca: Aspectos históricos, jurídicos e sociais. São Paulo: FTD, 72-102.

Waddington, Jeremy (1999), "Situating Labour within the Globalization Debate", in J. Waddington (org.), Globalization and Patterns of Labour Resistance. London: Mansell, 1-28.

Waddington, J.; Hoffmann, R.; Lind, J. (1997), “European Trade Unionism in Transition? A Review of Issues", Transfer-European Review of Labour and Research, 3(3), 464-497. 